\title{
Prolongation of the descending branch of the T-wave in electrocardiograms with no apparent data consistent with risk for sudden death
}

\author{
Cuauhtémoc Acoltzin-Vidal' and Elizabeth Rabling-Arellanos ${ }^{2}$ \\ ${ }^{1}$ Universidad de Colima, Faculty of Medicine; ${ }^{2}$ Private Cardiology Clinic; Gabinete de Pruebas Especiales, Colima, Mexico
}

\begin{abstract}
Introduction: Prolongation of the descending branch of the T-wave in the electrocardiogram (ECG) has been identified to be able to determine the risk for sudden death of cardiac origin, but its importance in the general population is not known. Objective: To provide a tool for easy acquisition and effective application to identify the risk of sudden death in the general population. Method: We measured the $d b T / j T$ index (descending branch of the $T$ wave/space between the j point and the end of T), and it was found to be completely normal in 400 ECGs, 656 had alterations that don't affect ventricular repolarization, and 82 had branch block. We carried out the $Z$ transformation of the nonparametric distribution curves and calculated the $Z$ ratio to data far from the mean value. Results: The distribution was asymmetric, with no difference in the three groups. The $Z$ transformation showed a mean value of $30 \pm 7$, which suggests that $95 \%$ of the population has a dbT/jT index $<0.45$. Conclusion: $d b T / j T$ index results $>0.44$ are beyond two standard deviations and are therefore abnormal, which should prompt specialized assessment in order to determine if there is risk for death in the carrier.
\end{abstract}

KEY WORDS: Electrocardiography. Cardiac sudden death. Long QT syndrome.

\section{Introduction}

In view of the impact represented by suddenly dying, identifying those who are at special risk has been tried since long ago. For that purpose, conditions such as myocardial infarction, aortic stenosis, pulmonary thromboembolism, asphyxia due to choking and others that cause sudden death have been described. Electrocardiographic syndromes such as Lange and Jervell-Nielsen, ${ }^{1}$ Romano-Ward, ${ }^{1}$ Brugada, ${ }^{2}$ and the now called $\mathrm{J}$-spot syndrome, ${ }^{3}$ as well as other entities based on transmembrane action potential disorders such as the existence of fractioned potentials, ${ }^{4}$ especially ventricular late potentials, ${ }^{4,5}$ have also been investigated. Repolarization disorders associated with ion channels malfunction at the cell membrane are of primary importance, including QT-interval lengthening or shortening, T-wave deformity and variability ${ }^{2}$ and prolongation of its descending branch duration, which differ from ventricular late potentials because they originate at different moments of cardiac electrical activity. While the latter are related to ventricular depolarization end, the former are associated with repolarization disorder.

Since nearly one decade ago, ${ }^{6}$ electrocardiogram (ECG) T-wave descending branch prolongation has been identified to be likely to identify the risk of cardiac-origin sudden death. This electrocardiographic anomaly has been studied in conditions that can cause sudden death such as long QTc ${ }^{7}$ or short QTc, ${ }^{8,9}$ but also in other entities such as heart failure, ${ }^{10}$ arrhythmogenic right ventricular cardiomyopathy, apnea, ${ }^{12}$ arterial hypertension ${ }^{13,14}$ and myocardial infarction. ${ }^{15,16}$ Its association with atrial fibrillation and death has been demonstrated, at least as infarction complications.
Correspondence:

Cuauhtémoc Acoltzin-Vidal

E-mail: cuauhtemoc_acoltzin@ucol.mx
Date of reception: 05-08-2017

Date of acceptance: 09-08-2017

DOI://dx.doi.org/10.24875/GMM.M18000130
Gac Med Mex. 2018;154:153-156

Contents available at PubMed www.gacetamedicademexico.com 
In the literature, the concept has been managed with different names, such as T/QT, ${ }^{6} \mathrm{QTe} / \mathrm{RR}$ and QTa/RR, ${ }^{10}$ Tpeak-end, ${ }^{16}$ TpTe, ${ }^{17}$ Tp-e, ${ }^{13} \mathrm{TPE}^{11}$ and Tpe, ${ }^{14}$ out of which the Tpeak-end/QT ${ }^{16}$ or Tpe/QT ${ }^{13}$ denominations have prevailed.

We proposed excluding ventricular (QRS) complex duration because intraventricular conduction delays would mislead the results by increasing the denominator magnitude; therefore, we subtracted that time and divided T-wave descending branch by the jT segment (measured from the j-point and until the end of T-wave), which we call the $\mathrm{dbT} / \mathrm{jT}$ index or Acoltzin-Rabling index.

\section{Problem statement}

It hasn't been clarified whether the $\mathrm{dbT} / \mathrm{j} \mathrm{T}$ index can be abnormal in population with no apparent risk of sudden death, and thus we ask: do electrocardiograms of people with no apparent risk of sudden death show $\mathrm{dbT} / \mathrm{jT}$ index alterations?

\section{Purpose of the study}

To provide an easily acquirable and effective tool to identify the risk of sudden death in the general population.

\section{Method}

Electrocardiograms obtained from individuals at rest, in the dorsal decubitus position with head elevated $30^{\circ}$ and measured by a single person aided by a magnifying glass, are included. Measurements included rhythm, rate, P-R, QRS, QTc; P, QRS and T electrical axis at frontal plane; ventricular voltage measurement with Cabrera, Lewis, Sokolow and Sokolow-Lion indices; P and QRS waves' morphology; ventricular repolarization characteristics such as ST segment and T-wave. QTc was calculated with Bazett's formula. Three separate groups were formed:

- All electrocardiograms (which were identified as GP, for general population).

- Electrocardiograms whose measurements were entirely normal (identified as $\mathrm{S}$, for selected).

- Electrocardiograms with QRS longer than $0.10 \mathrm{~s}$ (identified as BB, for branch block).

The $\mathrm{dbT} / \mathrm{jT}$ index was measured: duration from T-wave peak to the isoelectric line and duration from the j-point to T-wave end (at isoelectric line) and the

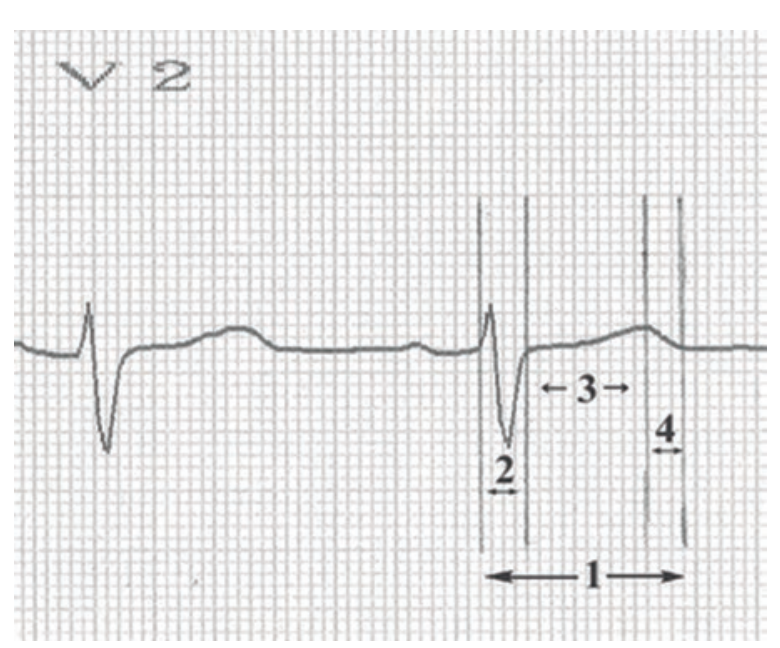

Figure 1. Example of electrocardiographic tracing measurement for $d b T / j T$ index calculation purposes. 1) Q-T space. 2) Ventricular or QRS complex. 3) J-T space. 4) T-wave descending branch.

division was made at each case. These values are reported as fractions (Figure 1).

Data distribution was plotted and compared for the three groups. Central tendency and dispersion measures were calculated for each group.

Group S Z-transformation was carried out (with mean value and standard deviation being calculated) in order to identify normality limits at 2 and 3 standard deviations from the mean.

The Z-value was calculated in order to identify the degree of abnormality of data located outside the curve.

\section{Results}

A total of 656 tracings were obtained from the sample population (SP), 400 were selected (S) and 82 had interventricular conduction disorders (BB).

Data distributions showed asymmetric, downward deflected curves in all three groups, with medians of 29 (GP), 29 (S) and 27 (BB) and modes of 28 (SP), 28 (S) and 26 (BB) (Table 1), with no statistically significant difference, using the U-test between groups.

$S$ group Z-transformation showed a mean value of $30 \pm 7$ (Table 2), suggesting that $95 \%$ of the population must have a $\mathrm{dbT} / \mathrm{jT}$ index lower than 0.45 , which can be accepted as normal, with inference to $99 \%$ of the population being made if the result is as high as 0.51 .

When the real data identified by group BB interquartile range were compared with this normalized curve, those corresponding to Q4 are at 5.14 standard deviations from the suggested population mean. Interestingly, PM group Q4 data are at 7.85 standard deviations 
Table 1. $\mathrm{dbT} / \mathrm{jT}$ index theoretical values normal distribution in selected population

\begin{tabular}{ccccccc}
\hline$-3 \mathrm{SD}$ & $-2 \mathrm{SD}$ & $-1 \mathrm{SD}$ & Mean & $+1 \mathrm{SD}$ & $+2 \mathrm{SD}$ & $+3 \mathrm{SD}$ \\
\hline 0.09 & 0.16 & 0.23 & 0.30 & 0.37 & 0.44 & 0.51 \\
\hline SD, standard deviation from the mean. Expressed as a fraction.
\end{tabular}

Table 2. $\mathrm{dbT} / \mathrm{jT}$ index values interquartile range in different groups

\begin{tabular}{lcccccc}
\hline & Q0 & Q1 & Median & Mode & Q3 & Q4 \\
\hline S & 0.11 & 0.25 & 0.28 & 0.29 & 0.33 & 0.65 \\
GP & 0.06 & 0.25 & 0.28 & 0.29 & 0.35 & 0.85 \\
BB & 0.14 & 0.22 & 0.26 & 0.27 & 0.37 & 0.66 \\
\hline
\end{tabular}

$\mathrm{Q}$, quartile. Q0 is the lowest data. Values expressed as fractions. S, with normal

measurements; GP, general population; BB, with branch block.

from the normal curve, but even more within group $S$, selected because all measurement results are normal; data at 5 standard deviations also do escape.

\section{Discussion}

The $\mathrm{dbT} / \mathrm{j} T$ index is an instrument that is easy to calculate and really useful.

Although QT interval measurement is also easy, correcting with the Bazett formula provided by the QTC indicator, which is much more manageable, is necessary in order to estimate its importance, although QTC duration changes can be of several types (shortening or lengthening) and these also have varieties; in addition, QT interval duration changes for many reasons, including the posture, body temperature and medications, ${ }^{18,19}$ which undermines its reliability.

Brugada's syndrome typical repolarization identification has been modified in such a way that, even when formerly it was classified in three types, now only one is accepted, and it is also inconstant. ${ }^{18}$

Late ventricular potentials appear at different moments of heart electrical activity, and although they have been shown to be important indicators of life threatening arrhythmias after myocardial infarction, ${ }^{16}$ they are even harder to identify: averaged signal special electrocardiographic equipment is required and, sometimes, ambulatory monitoring, ${ }^{20-23}$ which are available only at certain centers. The difficulty increases because sometimes alterations are observed at the end of R or at the beginning of the ST segment, which may correspond to epsilon wave, but also to noise. There is no absolute certainty.

Comparatively, the probability of ventricular fibrillation after myocardial infarction (mortal or non-mortal) in individuals with previously-identified late ventricular potentials has been reported to be $3.4 \%$, and related to them in the open population, it increases to $6.7 \%$, which indicates the existence of different associated risk factors. ${ }^{5}$ Conversely, the probability of post-infarction ventricular fibrillation associated with a higher " $T$ peak-end/QT" index is $6 \%{ }^{16}$

The reported results are theoretical, since in spite of electrocardiographic tracings having been selected, a non-parametric distribution was found and had to be transformed; however, they allow observing that, when the $\mathrm{dbT} / \mathrm{jT}$ index is calculated, there are tracings that are so distant of the expected mean value that might have special risk of ventricular fibrillation and sudden death.

As it has been exposed, risks for arrhythmia ${ }^{11,16}$ and death, ${ }^{10,17}$ even sudden death, ${ }^{10}$ have been demonstrated, and different results have been reported because absolute figures that have been generally measured as values above percentile 75 , corresponding to $>0.20$ for QTp/RR (Q to T-peak/R-R) or 0.23 for QTe/rr ( $Q$ to $T-e n d / R-R$ ) were considered to be abnormal, since they are associated with all-cause or sudden death in patients with heart failure, ${ }^{10} \mathrm{Tp}-\mathrm{e} / \mathrm{QT}$ index of $0.23 \pm 0.02$ in hypertensive subjects without nocturnal blood pressure dipping ${ }^{13}$ or $T$ peak-end/QT of $0.41 \pm 0.09$ in patients with myocardial infarction and ventricular fibrillation. ${ }^{16}$ However, one study carried out in dogs yielded a conflicting result, with TpTe index values lower than $98.76 \mathrm{~ms}$ in non-survivors. ${ }^{170}$

The report by Shenthar et al. ${ }^{16}$ suggests that T peakend/QT index highest acceptable value should be 0.3 , a value that in the theoretical distribution curve we obtained represents the mean. Moreover, the expected figure at one standard deviation above the mean value is 0.37 , which is absolutely normal. One possible explanation is that $T$ descending branch duration was compared with $\mathrm{QT}$, and QRS duration variations might change the result. We are in no position to categorically answer this because we always eliminated ventricular complex duration.

The $\mathrm{dbT} / \mathrm{j} T$ index looks as an accessible risk indicator, with higher easiness than fractionated potentials, such as late potentials, which require fractionated signal special, as well as reliable equipment, in comparison with QT interval simple measurement.

We propose resorting to the $\mathrm{dbT} / \mathrm{jT}$ index and exclusively referring to it in in order to avoid confusion in reports. Routinely measuring it in all electrocardiographic tracings and broadening the study of cases where it is higher than 0.44 ( $45 \%$ of $j \mathrm{~T}$ duration). 


\section{References}

1. Asensio E, Narváez R, Dorantes J, Oseguera J, Orea A, Hernández P et al. Conceptos actuales de muerte súbita. Gac Med Mex. 2005;141(2): 89-97.

2. Nieminen, T, Verrier, RL. Usefulness of T-Wave alternans in sudden death risk stratification and guiding medical therapy. Ann Noninvasive Electrocardiol. 2017;15(3):276-288

3. Abe A, Ikeda T, Tsukada T, Ishiguro H, Miwa $Y$, Miyakoshi M, et al. Circadian variation in late potentials in idiopathic ventricular fibrillation associated with $\mathrm{J}$ waves: insights into alternative pathophysiology and risk stratification. Heart Rhythm 2010;7(5):675-682.

4. Galix. Analizador de potenciales tardíos $L^{\circledR}{ }^{\circledast}$. Manual de operación. Disponible en: http://espanol.galix-gbi.com/images/pdf/Manuals/PTV-Manual-ES.pdf

5. Zimmermann M, Sentici A, Adamec R, Metzger J, Mermillod B, Rutishauser W. Long term prognostic significance of ventricular late potential after a first myocardial infarction. Am HeartJ. 1997;134(6):1019-1028.

6. Vidal CA, Rabling AE. El índice T/QT señala riesgo de electrocución de corazón. Rev Mex Cardiol. 2006;17(4):170.

7. Acoltzin-Vidal C, Rabling-Arellanos E. En el QTc largo la rama descendente de T mayor de 44\% es anormal. Rev Mex Cardiol. 2014;25(1):3-6

8. Acoltzin-Vidal C, Rabling-Arellanos E. Comportamiento del índice rdT/ST en casos de QTc corto comparado con QTc normal. Rev Mex Cardiol. 2008;19(4):208

9. Chinushi M, Sato A, Izumi D, Furushima H. Nifekalant enlarged the transmural activation-recovery interval difference as well as the peak-toend interval on surface ECG in a patient with short-QT syndrome. J Cardiovasc Electrophysiol.2012;23(8):877-880

10. Cygankiewics I, Zareba W, Vázquez R, Almendral J, Bayes-Genis A Fiol M, et al. Prognostic value of QT/RR slope in predicting mortality in patients with congestive Heart Failure. J Cardiovasc Electrophisiol. 2008;19(10):1066-1072.

11. Haapalahti $P$, Viitasalo $M$, Kaartinen $M$, Väänänen $H$, Oikarinen $L$, Heliö $T$, et al. Electrocardiographic ventricular repolarization during cardiovascular autonomic function testing in patients with arrhythmogenic right ventricular cardiomyopathy. Scand Cardiovasc J.2008 42(6):375-382.

12. Kilicaslan F, Tokatli A, Ozdag F, Uzun M, Uz O, Isilak Z, et al. Tp-e interval, Tp-e/QT ratio, and Tp-e/QTc ratio are prolonged in patients with moderate and severe obstructive sleep apnea. Pacing Clin Electrophysiol.2012;35(8):966-972.
13. Demir M, Uyan U. Evaluation of Tp-e interval and Tp-e/QT ratio in patients with non-dipper hypertension. Clin Exp Hypertens. 2014; 36(5):285-288.

14. Ciobanu A, Gheorghe GS, Ababei M, Deaconu M, llesiu A, Bolohan M, et al. Dispersion of ventricular repolarization in relation to cardiovascular risk factors in hypertension. J Med Life.2014;7(4):545-550.

15. Erikssen G, Liestøl K, Gullestad L, Huagaa KH, Bendz B, Amlie JP. The terminal part of the QT interval (T peak to $T$ end): a predictor of mortality after acute myocardial infarction. Ann Noninvasive Electrocardiol. 2012;17(2):85-94

16. Shenthar J, Deora S, Rai M, Nanjapa Manjunath C. Prolonged Tpeak-end and Tpeak-end/QT ratio as predictors of malignant ventricular arrhythmias in the acute phase of ST-segment elevation myocardial infarction: a prospective case-control study. Heart Rhythm. 2015; 12(3):484-489.

17. Smetana P, Schmidt A, Zabel M, Hnatkova K, Franz M, Huber K, et al. Assessment of repolarization heterogeneity for prediction of mortality in cardiovascular disease: peak to the end of the T wave interval and nondipolar repolarization components. J Electrocardiol. 2011; 44(3):301-308.

18. Iturralde-Torres P. Arritmias cardiacas. En: Martínez-Ríos MA. Tratado de Cardiología del Instituto de Nacional de Cardiología Ignacio Chávez. México: Intersistemas; 2012.

19. Guill A, Tormos A, Millet J, Roses EJ, Cebrian A, Such-Miquel L, et al. Heterogeneidades inducidas en el intervalo QT mediante enfriamiento/ calentamiento epicárdico local. Estudio experimental. Rev Esp Cardiol. 2014;67(12):993-998.

20. Simson MB. Noninvasive identification of patients at high risk of sudden cardiac death. Signal-averaged electrocardiography. Circulation. 1992;85(Suppl 1):145-151.

21. Reyna CMA, Vildósola RL. Aplicación de Kernels óptimos para mejorar la detección de actividad ventricular tardía. Rev Mex Ing Miomed. 2003; 24(1):71-76.

22. Abe A, Kobatashi K, Yuzawa H, Sato H, Fukunaga S, Fugino T, et al. Comparison of late potentials for 24 hours between Brugada syndrome and arrhythmogenic right ventricular cardiomyopathy using a novel signal-averaging system based on Holter ECG. Circ Arrhythm Electrophysiol. 2012;5(4):789-795.

23. Avitia RL, Reyna MA, Bravo-Zanoguera ME, Cetto LA. QRS complex duration enhancement as ventricular late potentials indicator by signal-averaged ECG using time-amplitude alignments. Biomed Tech (Berl). 2013:58(2):179-186. 